\title{
How well do we know the infaunal biomass of the continental shelf?
}

\author{
Eric N. Powell ${ }^{1}$ \\ Roger Mann ${ }^{2}$ \\ ${ }^{1}$ Gulf Coast Research Laboratory \\ University of Southern Mississippi \\ 703 East Beach Drive \\ Ocean Springs, MS 39564 \\ e-mail: eric.n.powell@usm.edu \\ ${ }^{2}$ Virginia Institute of Marine Sciences \\ The College of William and Mary \\ Rt. 1208 Greate Road \\ Gloucester Point, VA 23062-1346 \\ e-mail: rmann@vims.edu
}

Keywords: continental shelf, benthos, biomass, sampling design, sampling density, patchiness, bivalve

Highlights:

1. A numerical model simulated survey gear types and sampling densities.

2. Boxcore and grab samplers were simulated with the Atlantic surfclam as target.

3. Typical survey sampling designs produced highly inaccurate clam densities.

4. Increased clam patchiness produced surveys with large density estimation errors.

5. Biomass of large benthos may be routinely underestimated on the continental shelf.

\begin{abstract}
Benthic infauna comprise a wide range of taxa of varying abundances and sizes, but large infaunal taxa are infrequently recorded in community surveys of the shelf benthos. These larger, but numerically rare, species may contribute disproportionately to biomass, however. We examine the degree to which standard benthic sampling gear and survey design provide an adequate estimate of the biomass of large infauna using the Atlantic surfclam, Spisula solidissima, on the continental shelf off the northeastern coast of the United States as a test organism. We develop a numerical model that simulates standard survey designs, gear types, and sampling densities to evaluate the effectiveness of vertically-dropped sampling gear (e.g., boxcores, grabs) for estimating density of large species. Simulations of randomly distributed clams at a density of $0.5-1 \mathrm{~m}^{-2}$ within an $0.25-\mathrm{km}^{2}$ domain show that lower sampling densities
\end{abstract}


(1-5 samples per sampling event) resulted in highly inaccurate estimates of clam density with the presence of clams detected in less than $25 \%$ of the sampling events. In all cases in which patchiness was present in the simulated clam population, surveys were prone to very large errors (survey availability events) unless a dense (e.g., 100-sample) sampling protocol was imposed. Thus, commercial quantities of surfclams could easily go completely undetected by any standard benthic community survey protocol using vertically-dropped gear. Without recourse to modern high-volume sampling gear capable of sampling many meters at a swath, such as hydraulic dredges, biomass of the continental shelf will be grievously underestimated if large infauna are present even at moderate densities.

\section{Introduction}

Benthic infauna comprise a wide range of taxa of varying abundances and sizes. The literature records a rich and diverse record of benthic surveys in which abundance and biomass are reported, only a few of which will be referenced herein. Generally speaking, large animals contribute substantially more to community biomass than to community abundance (e.g., Staff et al., 1985). This trend suggests that estimates of benthic biomass should be designed to adequately sample the larger, but numerically rarer, infauna. We ask these questions here. How well do we achieve that goal? Do we really know the biomass of infauna on the continental shelf? We examine this question by using the Atlantic surfclam, Spisula solidissima, on the continental shelf off the northeastern coast of the United States as a test organism. This clam supports a major commercial fishery in this region (Weinberg, 1999, 2005). The density of these clams is well described based on stock surveys using hydraulic dredges with known and high efficiency of capture (Weinberg et al., 2005; Hennen et al., 2012). Dredge tows reported in Weinberg et al. (2005) typically sampled $1,375 \mathrm{~m}^{2}$. High density populations typically exist at densities of 0.5 to $2 \mathrm{~m}^{-2}$. Taking an 140-mm surfclam as a typical individual, this density contributes 14 to $56 \mathrm{~g} \mathrm{~m}^{-2}$ (Marzec et al., 2010) to benthic biomass, a biomass that is representative of typical samples obtained in many benthic surveys (e.g., Josefson and Hansen, 2004; Dubois et al., 2009; Bolam et al., 2010; Schonberg et al., 2014). Thus, successful sampling of these large clams, were they to be present in these densities, would constitute an important component of macroinfaunal biomass. 
To examine the potential for sampling and adequately quantitating clam density and hence biomass using gear and sampling densities typically employed in benthic survey designs, we developed a numerical model that simulates standard survey designs, gear types, and sampling densities. The model evaluates the effectiveness of vertically-dropped sampling gear (e.g., boxcores, grabs) for estimating density of large species such as surfclams. The model establishes a two-dimensional grid in which particles (clams) are dispersed either randomly or patchily. In the case of patches, the patches are distributed randomly, and the clams are distributed in a biased random fashion so that clams are more likely to be within a given distance from another clam than otherwise. The basic unit of the domain is $\mathrm{cm}$. Simulations for this study were conducted using a domain of 500x500 m. For the purposes of this exercise, clams were sampled using either a $25 \times 25-\mathrm{cm}$ or $50 \times 50-\mathrm{cm}$ sampling device, representing typical boxcore or grab sampling gear.

Simulated sampling locations within the domain are chosen randomly using Knuth's Ran1 random number generator (Press et al., 1986). Initial trials showed that small-scale autocorrelation (2-4 numbers in a row) occurred often enough to generate biased results in some cases. Thus all random numbers were re-randomized using an independent set of random numbers. We assume that surfclams expose an $8 \times 8-\mathrm{cm}$ surface to the sampling gear; that is, clams are oriented vertically in the anterior-posterior dimension, so that the exposure is expressed by the width and height of the clam rather than the length. Chosen sampling locations defined the northwest corner of the sample. By convention, any clam falling $>50 \%$ within the sampled area was considered sampled. For each simulation, the domain was seeded with enough clams to provide an average density of $0.5,1$, or 2 clams $\mathrm{m}^{-2}$, representative of typical and high densities for surfclams in the Mid-Atlantic Bight (NEFSC, 2010).

All simulated sampling was conducted using a random sampling protocol. We recognize that many biological surveys use fixed station designs (e.g., van der Meer, 1997; Petitgas and Lafont, 1997; Morehead et al., 2008) and are often transect based (e.g., Young and Rhoads, 1971; Flint and Holland, 1980; Dauer et al., 1984). King and Powell (2007) show that the uncertainties posed by insufficient sampling density, as discussed herein, plague sampling designs of the transect kind as they do random sampling designs. 
For patchy distributions, patchiness was defined in terms of the maximum distance permitted between one clam and a second. The domain was seeded with a given number of clams that defined the initial set of patches. Further clams were placed into patches if distance requirements were met by means of the drawing of a limited number of random numbers. If distance requirements were not met in the allotted number of draws, a new patch was initiated at a random location. This permitted expansion of the number of patches, while also permitting enlargement of and increased density in established patches. Patchiness was determined by estimating the variance-to-mean ratio of the number of clams in a complete series of nonoverlapping, but contiguous, samples of "sample-size" dimension (e.g., 50 x $50 \mathrm{~cm}$ ) covering the entire domain (Taylor, 1961; Elliott, 1977). The two example scales of patchiness used in this study are shown in Figures 1 and 2. Variance-to-mean ratios for simulations using these cases were about 1.6 and 2.5, respectively, based on contiguous sampling of the entire domain with a $25 \times 25-\mathrm{cm}$ sampling gear $(\mathrm{n}=4,000,000)$. Clam densities inside patches reached about 80 clams $\mathrm{m}^{-2}$ within a domain where average clam density was $1 \mathrm{clam} \mathrm{m}^{-2}$. Patches this dense have been observed during surveys (Mann, unpubl. data).

Edge effects were minimized by using a domain at least 1 million times larger than the sample volume. Choice of the northwest corner of the sampling gear to establish the location of sampling assured that samples would not overlap the northern and western domain boundary, limiting edge effects to the southern and eastern boundary. On occasion some fraction of a sample would lie beyond one of these latter boundaries. Examination of the difference between simulations excluding or including such samples revealed few and always minor differences, confirming that edge effects were inconsequential with the domain size employed. Similarly, simulation results varied little with variation in the seed number for the random number generator. Thus, only single results for each spatial distribution and sampling intensity are presented.

Each simulation included 1,000 trials. Clam density was calculated from the samples obtained by each of these trials and the trials ranked by the density estimated. Simulation results are presented as the clam density obtained for a series of percentile ranks obtained from the 1,000 trials. Thus, the $90^{\text {th }}$ percentile value represents the density obtained in the trial ranked as the $900^{\text {th }}$ by clam density. 
Sampling of randomly-occurring clams present at a density of $1 \mathrm{~m}^{-2}$ by either a $50 \times 50-\mathrm{cm}$ or a $25 \times 25-\mathrm{cm}$ boxcore or grab resulted in estimated clam densities near the true density for the interquartile half of all 100-sample sampling events (Figure 3). Not surprisingly, the larger sampling device performed modestly better. Ten samples per sampling event, a 10-fold reduction in sample density, resulted in a poorer performance for the larger gear and a marked deterioration of performance for the smaller gear. Lower sampling densities (1-5 samples per sampling event) resulted in highly inaccurate estimates of clam density with the presence of clams detected in less than $25 \%$ of the sampling events (Figure 3 ).

Moderate patchiness modified this pattern in specifics, but not in general outcome. Onehundred-sample events routinely returned adequate estimates of clam density. Ten-sample events performed poorly and distinctly more poorly in comparison to the case of randomly-distributed clams (Figure 4). Fewer samples per event (1-5) resulted in the failure to sample any clams in most cases. These trends were magnified in the cases where clam patchiness was even more intense (Figure 5). In all cases in which patchiness was present, surveys were prone to very large errors (survey availability events) without imposition of a dense (100-sample) sampling protocol. Generally, clam estimates biased high occurred more often for non-zero estimates, but estimates of zero were more commonplace. That is, sampling events were more likely to fail to observe clams at all, than obtain a biased estimate, whether high or low.

Results were modestly improved if clam density was doubled to $2 \mathrm{~m}^{-2}$ (Figure 6). Nonetheless, sampling intensities of 1 or 2 samples per $0.25 \mathrm{~km}^{2}$ rarely revealed the presence of these clams at all and almost never estimated clam density accurately. For patchy distributions, even an intensity of 5 samples per $0.25 \mathrm{~km}^{2}$ was gravely inadequate. Only the most intense sampling event provided adequate density estimates if clam density were only $0.5 \mathrm{~m}^{-2}$ (Figure 7). For these large bivalves, this density remains well within the densities supporting commercial fishing (e.g., surfclams - NEFSC, 2010). Lower, yet still high, sampling intensities of 1-2 per $0.25 \mathrm{~km}^{2}$, failed to reveal this clam in over $90 \%$ of such surveys. Thus, commercial quantities of clams could easily go completely undetected by any standard survey protocol using verticallydropped gear. 


\section{Representative Benthic Survey Designs}

Benthic surveys are carried out for varied purposes using various gear types and sampling densities. Sampling density can be expressed in terms of sample area per available area or the number of samples taken per area. Here, we review a few of these designs purposefully chosen haphazardly from the literature. We compare these sampling densities to the simulation results just summarized which were obtained from simulations in which $4-200.0625-\mathrm{m}^{2}$ or $0.25-\mathrm{m}^{2}$ samples were taken per $\mathrm{km}^{2}$ of domain, a sampling density ranging from $2.5 \times 10^{-7}$ to $5 \times 10^{-6} \mathrm{~km}^{2}$ sampled per $\mathrm{km}^{2}$ of domain.

Josefson and Hansen (2004) surveyed a series of Danish estuaries and coastal areas using a Haps corer of $0.01 \mathrm{~m}^{2}$. Sampling density was about $6.1 \times 10^{-8} \mathrm{~km}^{2}$ per $\mathrm{km}^{2}$, or about 4 samples per $\mathrm{km}^{2}$, similar to or lower than our simulated sampling designs. Dubois et al. (2009) sampled sandy shoals on the Louisiana continental shelf in the Gulf of Mexico using 3 replicates of a 900 $\mathrm{cm}^{2}$ GOMEX boxcore or a total of $0.27 \mathrm{~m}^{2}$ per sample. Stations were distributed in roughly a $50 \times 5 \mathrm{~km}$ region, a sampling density of $2.3 \times 10^{-8} \mathrm{~km}^{2}$ per $\mathrm{km}^{2}$, or about 0.08 samples per $\mathrm{km}^{2}$, much lower than densities used in our simulations. Bolam et al. (2010) sampled much of the continental shelf of the United Kingdom using an $0.1 \mathrm{~m}^{2}$ Day or Van Veen grab. At each site, 3 samples were collected within $50 \mathrm{~m}$, with sites approximately $44.5 \mathrm{~km}$ apart, equivalent to about $1.5 \times 10^{-3}$ samples per $\mathrm{km}^{2}$ or a sampling density of about $2 \times 10^{-10} \mathrm{~km}^{2}$ per $\mathrm{km}^{2}$. This sampling density is much sparser than used in our simulations. Schonberg et al. (2014) sampled the northeast Chukchi Sea using replicate $\left(0.1 \mathrm{~m}^{2}\right)$ Van Veen grabs. Stations were about $19 \mathrm{~km}$ apart, about $2.8 \times 10^{-3}$ samples per $\mathrm{km}^{2}$ or a sampling density of about $6 \times 10^{-10} \mathrm{~km}^{2}$ per $\mathrm{km}^{2}$. Aller et al. (2002) sampled the continental shelf off Cape Hatteras, North Carolina using a variety of boxcores yielding $0.0049 \mathrm{~m}^{2}$ to $0.016 \mathrm{~m}^{2}$ depending on gear details. A number of transects were sampled. On one transect, 4 stations were occupied over a distance of about $2 \mathrm{~km}$, about 2 samples per $\mathrm{km}^{2}$ or approximately $2 \times 10^{-8} \mathrm{~km}^{2}$ per $\mathrm{km}^{2}$. Escobar-Briones and Soto (1997) sampled the Texas continental shelf using 2-3 replicate $0.2 \mathrm{~m}^{2}$ Smith-McIntyre grabs per station with stations about 0.25 degrees of latitude apart, yielding a sampling frequency of $1.3 \times 10^{-3}$ per $\mathrm{km}^{2}$ or a sampling density of about $6 \times 10^{-10} \mathrm{~km}^{2}$ per $\mathrm{km}^{2}$.

The purpose of this summary is to merely point out that typical sampling gear has a 
sampling area no higher than our highest gear sample size of $0.25 \mathrm{~m}^{2}$ and typical sampling densities are near to much below the lower sampling densities of $1-2$ per $0.25 \mathrm{~km}^{2}$ used in our simulations which failed to yield a single clam in over $90 \%$ of the simulated surveys.

\section{The Implications of Limited Sampling}

The limitations imposed by inadequate sample density, particularly for patchilydistributed species, are well described (e.g., Findlay, 1982; Smith and Gavaris, 1993; Brown, 2003). King and Powell (2007) identified variations in the spatial dimension and shape of patches that elicited a significant tendency for predictably biased-low density estimates or that favored a high occurrence rate of biased-low and biased-high density estimates, given inadequate sampling. As sampling densities are rarely very high, these survey availability events are commonplace occurrences for many species. However, the failure to identify species as present or to inordinately downweigh their importance is an outcome much less often identified.

The sampling densities examined in this simulation study are relatively high even at the low sampling densities of 1-5 per sampling event, 4-20 samples per $\mathrm{km}^{2}$. This is a sampling intensity of $2.5 \times 10^{-7}$ to $5 \times 10^{-6} \mathrm{~km}^{2}$ per $\mathrm{km}^{2}$. Very rarely are sampling densities above this sampling density employed in benthic surveys, and good estimates required sampling at $1 \times 10^{-4}$ $\mathrm{km}^{2}$ per $\mathrm{km}^{2}$, a sampling density very rarely utilized. Thus, we investigate a series of spatially relatively intense sampling protocols. On the other hand, the gear used, providing samples of 0.25 and $0.0625 \mathrm{~m}^{2}$, is representative of standard sampling instruments.

Can we expect gear of this kind to provide accurate biomass estimates of large and longlived infaunal animals on the continental shelf? The answer is simply no! Even under dense sampling protocols, the chance of capture of even a single large bivalve, present at a rather high density of $1 \mathrm{~m}^{-2}$, is low. Thus, without recourse to modern high-volume sampling gear capable of sampling many meters at a swath, such as hydraulic dredges, infaunal biomass of the continental shelf often will be grievously underestimated if large infauna are present even at moderate densities.

Moreover, the simulations reveal an interesting pattern of low- and high-availability events, that is underestimates and overestimates of biomass, consistent with the results of King and Powell (2007) who found that either species were routinely underestimated or that high- and low-availability events occurred with relatively equivalent probability. No cases were observed 
where high-availability events were the commonplace occurrence. In our simulations, low sample density produced low-availability events routinely. Somewhat increased sample density increased the probability of high-availability events, but no simulation produced a bias towards high-availability events. Thus, the mismatch of sample density and patch dynamics will rarely result in the consistent overestimate of biomass, but commonly result in the consistent underestimate of biomass.

Staff et al. (1985) stressed the importance of filter feeders in the benthos of the continental shelf (and elsewhere) when community structure was based on biomass rather than abundance. Bivalves, today's dominant filter feeders and the only filter feeders routinely capable of spatially extensive top-down control of primary production (e.g. Roditi et al., 1996; Jonsson et al., 2005; Powell et al., 2012b), typically are large in comparison to most other benthic denizens. Not surprisingly, bivalve biomass averages high relative to other contributing groups to the benthic community, but production:biomass ratios average low (Cusson and Bourget, 2005) because bivalves tend to be long-lived. In keeping with their tendency towards large size, bivalves also trend towards being numerically relatively rare (Staff et al., 1985). Being dominantly, though not exclusively, infaunal (Nicol, 1968, 1970; Lockwood, 2004), their lifestyle and role in community structure both auger against the routine adequacy of their sampling to sustain accurate estimates of their role in community biomass and energy flow. What penalties follow?

Large bivalves are bellwethers of environmental change. They record in their growth and population dynamics changes in environmental conditions (Jones et al., 1989; Ivany et al., 2003 Butler et al., 2009). A selection of them rank among the oldest of noncolonial animals (e.g., Peterson, 1983; Powell and Cummins, 1985; Goodwin and Pease, 1989; Philipp and Abele, 2009). Being particularly sensitive to environmentally-enforced shifts in range (Roy et al., 2001; Kim and Powell, 2004; Munroe et al., 2013), such bivalves offer an early warning system for ecologically significant reorganizations of continental shelf community structure (e.g., Roy et al., 2001; Dahlgren et al., 2000; Weinberg, 2005). Such range shifts are anticipated to be of particularly large scale towards the poles (Parmesan and Yohe, 2003). The effects of climate change, though becoming predictable in the physical world (e.g., Bojariu and Gimeno 2003; Keenlyside et al., 2008), remain resistant to predictive modeling in the biological world, due to thresholds in physiological and ecological response surfaces (e.g., Cognie et al., 2006; 

changes in community dynamics. They are the "canaries in the coal mine" for benthic ecology.

Large bivalves are also routinely employed as sentinel species for monitoring ecosystem health (e.g., Green et al., 1983; O’Connor, 1996; Rittschof and McClellan-Green, 2005) and we predict that they will be found to contribute disproportionately to the carbonate budget of the continental shelf benthos. They are at the nexus of the feedback between community dynamics and the benthic carbonate budget (e.g., Kidwell, 1986; Tomašových et al., 2006; Powell et al., 2012a). Thus, no carbonate budget for the continental shelf can be accurately formulated without reliable estimates of their biomass and shell production. They may prove also to be early warnings of ocean acidification (e.g., Gazeau et al. 2007; Beniash et al., 2010; Talmage and Gobbler, 2010; Waldbusser et al., 2013). Thus, chronic underestimation of their abundance and biomass not only impairs a basic understanding of shelf community dynamics, but also constrains a significant range of potential ecosystem analyses.

Defeating patchiness through sampling design is an ongoing goal (e.g., Venette et al., 2002; Pennington, 2003; King and Powell, 2007). King and Powell (2007) showed that not only the spatial extent and intensity of patches, but also patch shape, persistently compromise survey estimates. One obvious solution is to increase sample number or the areal coverage of sampling gear. Our simulations suggest that a simple increase in sample number is normally not an option as obtaining an acceptable estimate of density for sparse or patchy fauna would require a factor of 10 or greater increase in sampling intensity. A second obvious solution is to increase the areal coverage per sample by the use of a dredge. Obtaining quantitative estimates of infaunal benthos using dredges has proven to be difficult, however, as most dredges do not sample with $100 \%$ efficiency and efficiency tends to vary as the dredge fills (Mituhasi et al., 2005; Hennen et al., 2012).

Can we identify regions where grave underestimates may have occurred and impose adaptive survey methodologies to improve the reliability of biomass estimates? One option is to seek clues from the death assemblage. Both fidelity in species composition and rank-order abundance between the living community and the death assemblage are well documented (Staff et al., 1986; Kidwell, 2002, 2008; Lockwood and Chastant, 2006). Large clams for the most part are well preserved (Callender et al., 1994; Powell et al., 2011). Spatial and temporal averaging in 
the death assemblage usefully break down spatial patchiness (Powell et al., 1989; Lyman 2003; Kidwell, 2008; Tomašových and Kidwell, 2010). Thus, reduced sampling intensity is required to identify regions where large bivalves may be, or have been abundant. At the same time, critical information on the carbonate content of the surficial sediments is obtained. Including the death assemblage in an adaptive survey protocol to optimize survey effort for continental shelf biomass dominants should be a considered option.

\section{Acknowledgements}

We acknowledge funding from the National Science Foundation Industry/University Cooperative Research Center SCeMFiS (Science Center for Marine Fisheries: http://www.SCeMFiS.org).

\section{Literature Cited}

Aller, J.Y., Aller, R.C., Green, M.A., 2002. Benthic faunal assemblages and carbon supply along the continental shelf/shelf break-slope off Cape Hatteras, North Carolina. Deep Sea Res II Top. Stud. Oceanogr. 49, 44599-4625.

Beaugrand, G., Edwards, M., Brander, K., Laczak, C., Ibañez, F., 2008. Causes and projections of abrupt climate-driven ecosystem shifts in the North Atlantic. Ecol. Lett. 11, 1157-1168.

Beniash, E., Ivanina, A., Lieb, N.S., Kurochkin, I., Okolona, I.M., 2010. Elevated level of carbon dioxide affects metabolism and shell formation in oysters Crassostrea virginica. Mar. Ecol. Prog. Ser. 419, 95-108.

Bojariu, R., Gimeno, L. 2003. Predictability and numerical modelling of the North Atlantic Oscillation. Earth-Sci. Rev. 63, 145-168.

Bolam, S.G., Barrio-Frojan, C.R.S., Eggleton, J.D., 2010. Macrofaunal production along the UK continental shelf. J. Sea Res. 64, 166-179.

Brown, J.A., 2003. Designing an efficient adaptive cluster sample. Environ. Ecol. Stat. 10, 95105.

Butler, P.G., Richardson, C.A., Scourse, J.D., Witbaard, R., Schöne, B.R., Fraser, N.M., Wanamaker Jr., A.D., Bryant, C.L., Harris, I., Robertson, I., 2009. Accurate increment 
identification and the spatial extent of the common signal in five Arctica islandica chronologies from the Fladen Ground. northern North Sea. Paleoeanography 24, 1-18.

Callender, W.R., Powell, E.N., Staff, G.M., 1994. Taphonomic rates of molluscan shells placed in autochthonous assemblages on the Louisiana continental slope. Palaios 9, 60-73.

Cognie, B., Haure, J., Barillé, L., 2006. Spatial distribution in a temperate coastal ecosystem of the wild stock of the farmed oyster Crassostrea gigas (Thunberg). Aquaculture 259, 249259.

Cusson, M., Bourget, E., 2005. Global patterns of macroinvertebrate production in marine benthic habitats. Mar. Ecol. Prog. Ser. 297, 1-14.

Dahlgren, T.G., Weinberg, J.R., Halanych, K.M. 2000. Phylogeography of the ocean quahog (Arctica islandica): influences of paleoclimate on genetic diversity and species range. Mar. Biol. 137:487-495.

Dauer, D.M., Stokes Jr, T.L., Barker Jr, H.R., Ewing, R.M., Sourbeer, J.W., 1984. Macrobenthic communities of the lower Chesapeake Bay. IV. Bay-wide transects and the inner continental shelf. Int. Rev. Gesamten Hydrobiol. 69, 1-22.

Dubois, S., Gelpi, C.G., Condrey, R.E., Grippo, M.A., Fleeger, J.W., 2009. Diversity and composition of macrobenthic community associated with sandy shoals of the Louisiana continental shelf. Biodivers. Conserv. 18, 3759-3784.

Elliott, J.M., 1977. Some methods for the statistical analysis of samples of benthic invertebrates. Freshwater Biological Association Scientific Publ. 25, 1-157.

Escobar-Briones, E.G., Soto, L.A., 1997. Continental shelf benthic biomass in the western Gulf of Mexico. Cont. Shelf Res. 17, 585-604.

Findlay, S.E., 1982. Influence of sampling scale on apparent distribution of meiofauna on a sandflat. Estuaries 5, 322-324.

Flint, R., Holland, J. 1980. Benthic infaunal variability on a transect in the Gulf of Mexico. Estuar. Coast. Mar. Sci. 10, 1-14.

Gazeau, F., Quibiler, C., Jansen, J.M., Gattuso, J-P., Middelburg, J.J., Heip, C.H.R., 2007. Impact of elevated $\mathrm{CO}_{2}$ on shellfish calcification. Geophys. Res. Lett. 34:L07603, 5 pp. 
Goodwin, C.L., Pease, B., 1989. Species profiles: life histories and environmental requirements of coastal fishes and invertebrates (Pacific northwest) Pacific geoduck clam. U.S. Fish. Wildl. Serv. Biol. Rpt. 82(1-14); U.S. Army Corps Engineers TR EL-82-4.

Green, R.H., Singh, S.M., Bailey, R.C., 1983. Bivalve molluscs as response systems for modelling spatial and temporal environmental patterns. Sci. Total Environ. 46, 147-169.

Hennen, D.R., Jacobson, L.D., Tang, J., 2012. Accuracy of the Patch model used to estimate density and capture efficiency in depletion experiments for sessile invertebrates and fish. ICES J. Mar. Sci. 69, 240-249.

Ivany, L., Wilkinson, B.H., Jones, D.S., 2003. Using stable isotopic data to resolve rate an duration of growth throughout ontogeny: an example from the surf clam, Spisula solidissima. Palaios 18, 126-137.

Jones, J.R., Cameron, B., Rollins, H.B., 1989. Paleoecological implications of cohort survivorship for Mya arenaria in Massachusetts estuarine waters. Palaios 4, 468-474.

Jonsson, P.R., Peterson, J.K., Karlsson, Ö.J.K., Loo, L-O., Nilsson, S., 2005. Particle depletion above experimental bivalve beds: in situ measurements and numerical modeling of bivalve filtration in the boundary layer. Limnol. Oceanogr. 50, 1989-1998.

Josefson, A.B., Hansen, J.L.S., 2004. Species richness of benthic macrofauna in Danish estuaries and coastal areas. Global Ecol. Biogeogr. 13, 273-288.

Keenlyside, N.S., Latif, M., Jungclaus, J., Kornblueh, L., Roeckner, E., 2008. Advancing decadal-scale climate prediction in the North Atlantic sector. Nature (Lond.) 453, 84-88.

Kidwell, S.M., 1986. Taphonomic feedback in Miocene assemblages; testing the role of dead hardparts in benthic communities. Palaios 1, 239-255.

Kidwell, S.M., 2002. Time-averaged molluscan death assemblages: palimpsests of richness, snapshots of abundance. Geology 30, 803-806.

Kidwell, S.M., 2008. Ecological fidelity of open marine molluscan death assemblages: effects of post-mortem transportation, shelf health, and taphonomic inertia. Lethaia 41, 199-217.

Kim, Y., Powell, E.N., 2004. Surfclam histopathology survey along the Delmarva mortality line. J. Shellfish Res. 23, 429-441. 
King, S.E., Powell, E.N., 2007. Influence of adaptive stations in a transect-based sampling design for a multispecies fish survey. Fish. Res. 86, 241-261.

Lockwood, R., 2004. The K/T event and infaunality: morphological and ecological patterns of extinction and recovery in veneroid bivalves. Paleobiology 30, 507-521.

Lockwood, R., Chastant, L.R., 2006. Quantifying taphonomic bias of compositional fidelity, species richness, and rank abundance in molluscan death assemblages from the upper Chesapeake Bay. Palaios 21, 376-383.

Lyman, R.L., 2003. The influence of time averaging and space averaging on the application of foraging theory in zooarchaeology. J. Archaeol. Sci. 30, 595-610.

Marzec, R.J., Kim, Y., Powell, E.N., 2010. Geographic trends in weight and condition index of surfclams (Spisula solidissima) in the Mid-Atlantic Bight. J. Shellfish Res. 29, 117-128.

Mituhasi, T., Kitakado, T., Hu, F., Tokai, T., 2005. Modeling the contact probability and sizeselectivity of toothed dredges. Fish. Sci. 71, 703-712.

Morehead, S., Montaga, P., Kennicutt II, M., 2008. Comparing fixed-point and probabilistic sampling designs for monitoring the marine ecosystem near McMurdo Station, Ross Sea, Antarctica. Ant. Sci. 20, 471-484.

Munroe D.M., Powell, E.N., Mann, R., Klinck, J.M., Hofmann, E.E., 2013. Underestimation of primary productivity on continental shelves: evidence from maximum size of extant surfclam (Spisula solidissima) populations. Fish. Oceanogr. 22, 220-233.

NEFSC. 2010. $49^{\text {th }}$ Northeast Regional Stock Assessment Workshop (49 ${ }^{\text {th }}$ SAW) assessment summary report. NEFSC Ref. Doc. 10-01; 41 pp.

Nicol, D., 1968. Are pelecypods primarily infaunal animals? Nautilus 82, 37-43.

Nicol, D., 1970. Pelecypods, successful invaders of the infauna. Nautilus 84, 75-77.

O'Connor, T.P., 1996. Trends in chemical concentrations in mussels and oysters collected along the U.S. coast from 1986 to 1993. Mar. Environ. Res. 41, 183-200.

Parmesan, C., Yoho, G., 2003. A globally coherent fingerprint of climate change impacts across natural systems. Nature (Lond.) 421, 37-42. 
Pennington, J.B., 2003. Transcending patchiness in the comparative analysis of paleocommunities: a test case from the Upper Cretaceous of New Jersey. Palaios 18, 22-33.

Peterson, C.H., 1983. A concept of quantitative reproductive senility: application to the hard clam, Mercenaria mercenaria (L.)? Oecologica (Berl.) 58, 164-168.

Petitgas, P., Lafont, T. 1997., EVA2: Estimation variance. Version 2. A geostatistical software on Windows 95 for precision of fish stock assessment surveys. Int. Council Explor. Sea ICES CM-1997/Y:22, 22 pp.

Philipp, E.E.R., Abele, D., 2009. Masters of longevity: lessons from long-lived bivalves - a mini-review. Gerontology doi 10.159/000221004, 11 pp.

Powell, E.N., Cummins, H.C., 1985. Are molluscan maximum life span determined by long-term cycles in benthic communities? Oecologia (Berl.) 67, 177-182.

Powell, E.N., Kreeger, D.A., Morson, J.M., Haidvogel, D.B., Wang, Z., Thomas, R., Gius, J.E., 2012b. Oyster food supply in Delaware Bay: estimation from a hydrodynamic model and interaction with the oyster population. J. Mar. Res. 70, 469-503.

Powell, E.N., Klinck, J.M., Ashton-Alcox, K., Hofmann, E.E., Morson, J.M., 2012a. The rise and fall of Crassostrea virginica oyster reefs: the role of disease and fishing in their demise and a vignette on their management. J. Mar. Res. 70, 559-567.

Powell, E.N., Staff, G.M., Callender, W.R., Ashton-Alcox, K.A., Brett, C.E., Parsons-Hubbard, K.M., Walker, S.E., Raymond, A., 2011 Taphonomic degradation of molluscan remains during thirteen years on the continental shelf and slope of the northwestern Gulf of Mexico. Palaeogeogr. Palaeoclimatol. Palaeoecol. 312, 209-232.

Powell, E.N., Staff, G.M., Davies, D.J., Callender, W.R., 1989. Macrobenthic death assemblages in modern marine environments: formation, interpretation and application. Crit. Rev. Aquat. Sci. 1, 555-589.

Press, W.H., Flannery, B.P., Teukolsky, S.A., Vettering, W.T., 1986. Numerical recipes, the art of scientific computing. Cambridge University Press, Cambridge, 702 pp.

Rittschof, D., McClellan-Green, P., 2005. Molluscs as multidisciplinary models in environment toxicology. Mar. Pollut. Bull. 50, 369-373. 
Roditi, H.A., Caraco, N.F., Cole, J.J., Strayer, D.L., 1996. Filtration of Hudson River water by the zebra mussel (Dreissena polymorpha). Estuaries 19, 824-832.

Roy, K., Jablonski, D., Valentine, J.W., 2001. Climate change, species range limits and body size in marine bivalves. Ecol. Lett. 4, 366-370.

Schonberg, S.V., Clarke, J.T., Dunton, K.H., 2014. Distribution, abundance, biomass and diversity of benthic infauna in the northeast Chukchi Sea, Alaska: relation to environmental variables and marine mammals. Deep Sea Res. II Top. Stud. Oceanogr. 102, 144-163.

Smith, S.J., Gavaris, S., 1993. Improving the precision of abundance estimates of eastern Scotian Shelf Atlantic cod from bottom trawl surveys. N. Am. J. Fish. Manage. 13, 35-47.

Staff, G., Powell, E.N., Stanton Jr. R.J., Cummins, H., 1985. Biomass: is it a useful tool in paleocommunity reconstruction? Lethaia 18, 209-232.

Staff, G.M., Stanton Jr., R.J., Powell, E.N., Cummins, H., 1986. Time-averaging, taphonomy and their impact on paleocommunity reconstruction: death assemblages in Texas bays. Geol. Soc. Am. Bull. 97, 428-443.

Talmage, S.C., Gobler, C.J., 2010. Effects of past, present, and future ocean carbon dioxide concentrations on the growth and survival of larval shellfish. Proc. Natl. Acad. Sci. U.S.A. $107,17246-17251$.

Taylor, L.R., 1961. Aggregation, variance and the mean. Nature (Lond.). 189, 732-735.

Tomašových, A., Fürsich, F.T., Wilmsen, M., 2006. Preservation of autochthonous shell beds by positive feedback between increased hardpart-input rates and increased sedimentation rates. J. Geol. 114, 287-312.

Tomašových, A., Kidwell, S.M., 2010. Predicting the effects of increasing temporal scale on species composition, diversity, and rank-abundance distributions. Paleobiology 36, 672-695.

Van der Meer, J., 1997., Sampling design of monitoring programmes for marine benthos: a comparison between the use of fixed versus randomly selected stations. J. Sea Res. 37, 167-179.

Venette, R.C., Moon, R.D., Hutchison, W.D., 2002. Strategies and statistics of sampling for rare individuals. Annu. Rev. Entomol. 47, 143-174. 
Waldbusser, G.G., Powell, E.N., Mann, R. 2013. Ecosystem effects of shell aggregations and cycling in coastal waters: an example of Chesapeake Bay oyster reefs. Ecology 94:895903.

Weinberg, J.R., 1999. Age-structure, recruitment, and adult mortality in populations of the Atlantic surfclam, Spisula solidissima, from 1978-1997. Mar. Biol. 134, 113-125.

Weinberg, J.R., 2005. Bathymetric shift in the distribution of Atlantic surfclams: response to warmer ocean temperatures. ICES J. Mar. Sci. 62, 1444-1453.

Weinberg, J.R., Powell, E.N., Pickett, C., Nordahl Jr., V.A., Jacobson, L.D., 2005. Results from the 2004 cooperative survey of Atlantic surfclams. NEFSC Ref. Doc. 05-01, 1-41.

Young, D.K., Rhoads, D.C., 1971. Animal-sediment relations in Cape Cod Bay, Massachusetts I. A transect study. Mar. Biol. 11, 242-254. 
Figure 1. A selected portion of the $0.25-\mathrm{km}^{2}$ domain for the case of a highly patchy population (variance-to-mean ratio $=2.5$ ). Each grid square is $25 \times 25 \mathrm{~cm}$, the size of a typical boxcore or grab sample. Axis labels are arbitrary locations in the entire 2,000 x 2,000grid domain $(2,000$ grids $\times 25 \mathrm{~cm}=500 \mathrm{~m})$. Gray scale defines clam density. Highest densities reach about 80 clams $\mathrm{m}^{-2}$; overall density average is $1 \mathrm{clam} \mathrm{m}^{-2}$.

Figure 2. A selected portion of the $0.25-\mathrm{km}^{2}$ domain for the case of a moderately patchy population (variance-to-mean ratio $=1.6$ ). Each grid square is $25 \times 25 \mathrm{~cm}$, the size of a typical boxcore or grab sample. Axis labels are arbitrary locations in the entire 2,000 $\mathrm{x}$ 2,000-grid domain $(2,000$ grids $\times 25 \mathrm{~cm}=500 \mathrm{~m})$. Gray scale defines clam density. Highest densities reach about 80 clams $\mathrm{m}^{-2}$; overall density average is $1 \mathrm{clam} \mathrm{m}^{-2}$.

Figure 3. Estimated surfclam density for a randomly distributed surfclam population present at 1 $\mathrm{m}^{-2}$ in a $0.25-\mathrm{km}^{2}$ domain sampled by either a $0.125-\mathrm{m}^{2}$ or a $0.25-\mathrm{m}^{2}$ boxcore using five different sampling densities in which 1 to 100 samples were taken within the 0.25 $\mathrm{km}^{2}$ domain. The dashed line marks the true clam density in the domain: $1 \mathrm{clam} \mathrm{m}^{-2}$.

Figure 4. Estimated surfclam density for a moderately patchy surfclam population (Figure 2) present at $1 \mathrm{~m}^{-2}$ in a $0.25-\mathrm{km}^{2}$ domain sampled by either a $0.125-\mathrm{m}^{2}$ or a $0.25-\mathrm{m}^{2}$ boxcore using five different sampling densities in which 1 to 100 samples were taken within the $0.25-\mathrm{km}^{2}$ domain. The dashed line marks the true clam density in the domain: 1 clam $\mathrm{m}^{-2}$.

Figure 5. Estimated surfclam density for a highly patchy surfclam population (Figure 1) present at $1 \mathrm{~m}^{-2}$ in a $0.25-\mathrm{km}^{2}$ domain sampled by either a $0.125-\mathrm{m}^{2}$ or a $0.25-\mathrm{m}^{2}$ boxcore using five different sampling densities in which 1 to 100 samples were taken within the 0.25 $\mathrm{km}^{2}$ domain. The dashed line marks the true clam density in the domain: $1 \mathrm{clam} \mathrm{m}^{-2}$.

Figure 6. Estimated surfclam density for a randomly distributed, moderately patchy, and highly patchy surfclam population present at $2 \mathrm{~m}^{-2}$ in a $0.25-\mathrm{km}^{2}$ domain sampled by a 0.125 $\mathrm{m}^{2}$ boxcore using five different sampling densities in which 1 to 100 samples were taken within the $0.25-\mathrm{km}^{2}$ domain. The dashed line marks the true clam density in the domain: 2 clams $\mathrm{m}^{-2}$.

Figure 7. Estimated surfclam density for a randomly distributed, moderately patchy, and highly 
patchy surfclam population present at $0.5 \mathrm{~m}^{-2}$ in a $0.25-\mathrm{km}^{2}$ domain sampled by a $0.125-\mathrm{m}^{2}$ boxcore using five different sampling densities in which 1 to 100 samples were taken within the $0.25-\mathrm{km}^{2}$ domain. The dashed line marks the true clam density in the domain: 0.5 clams $\mathrm{m}^{-2}$. 


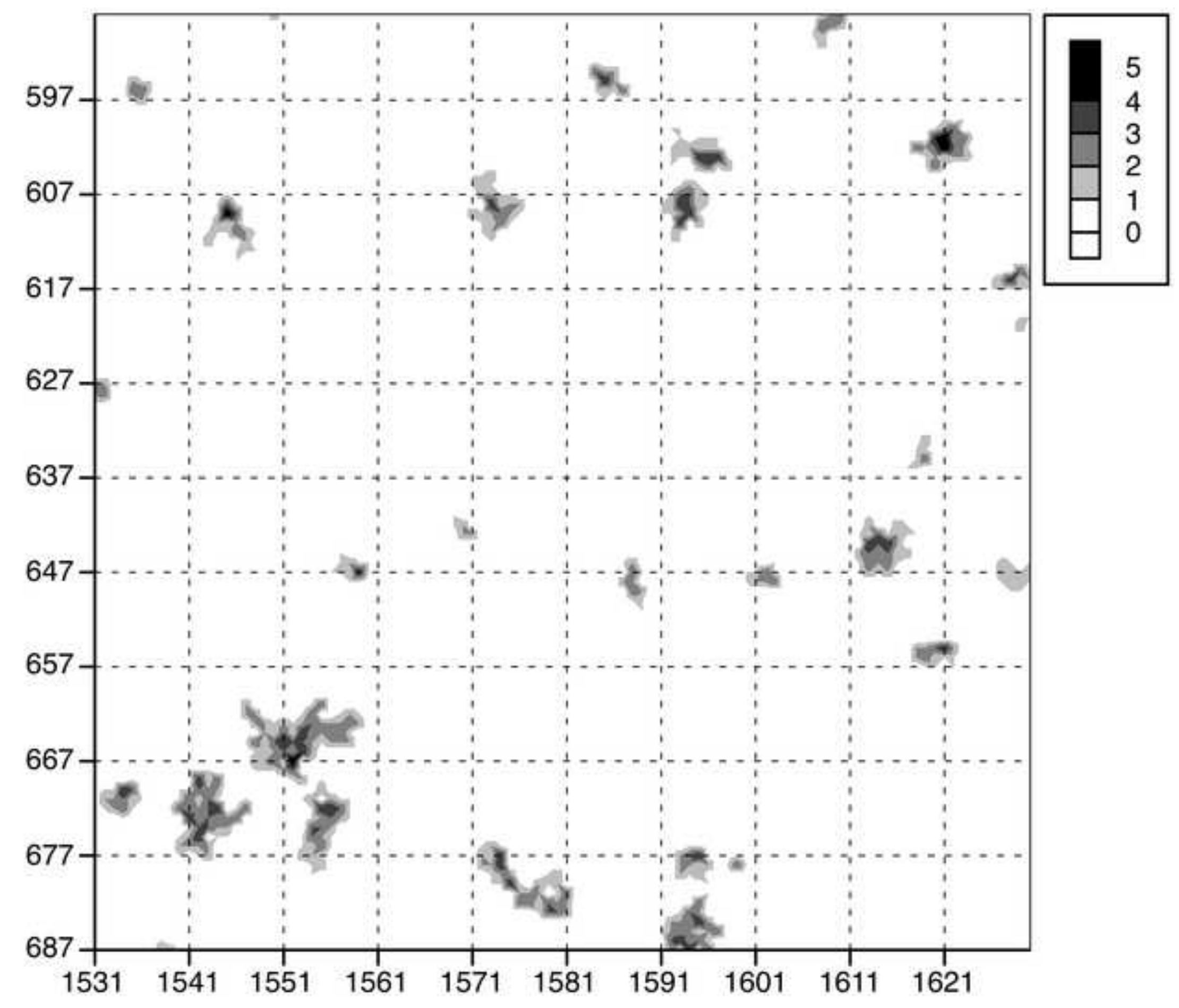




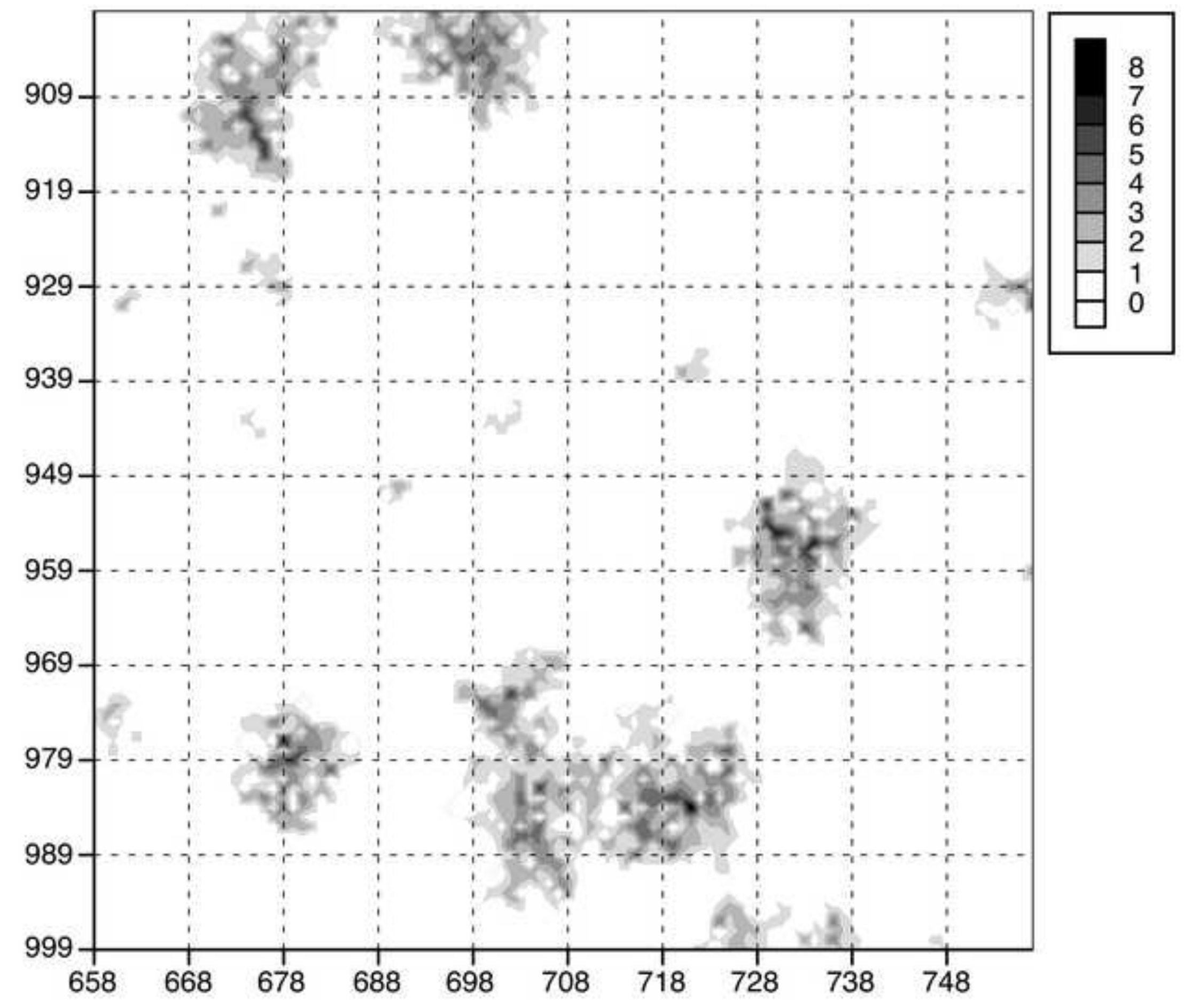




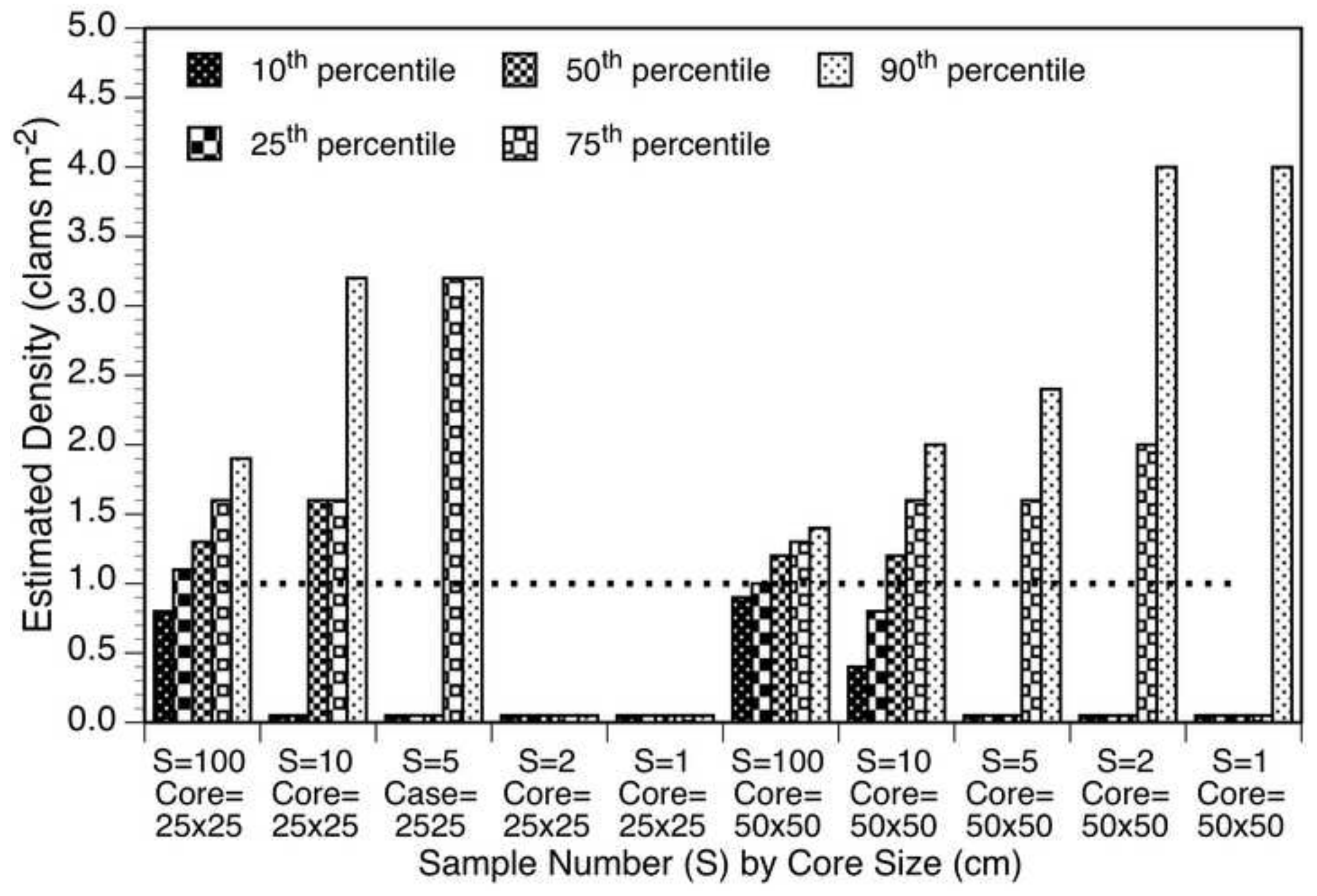




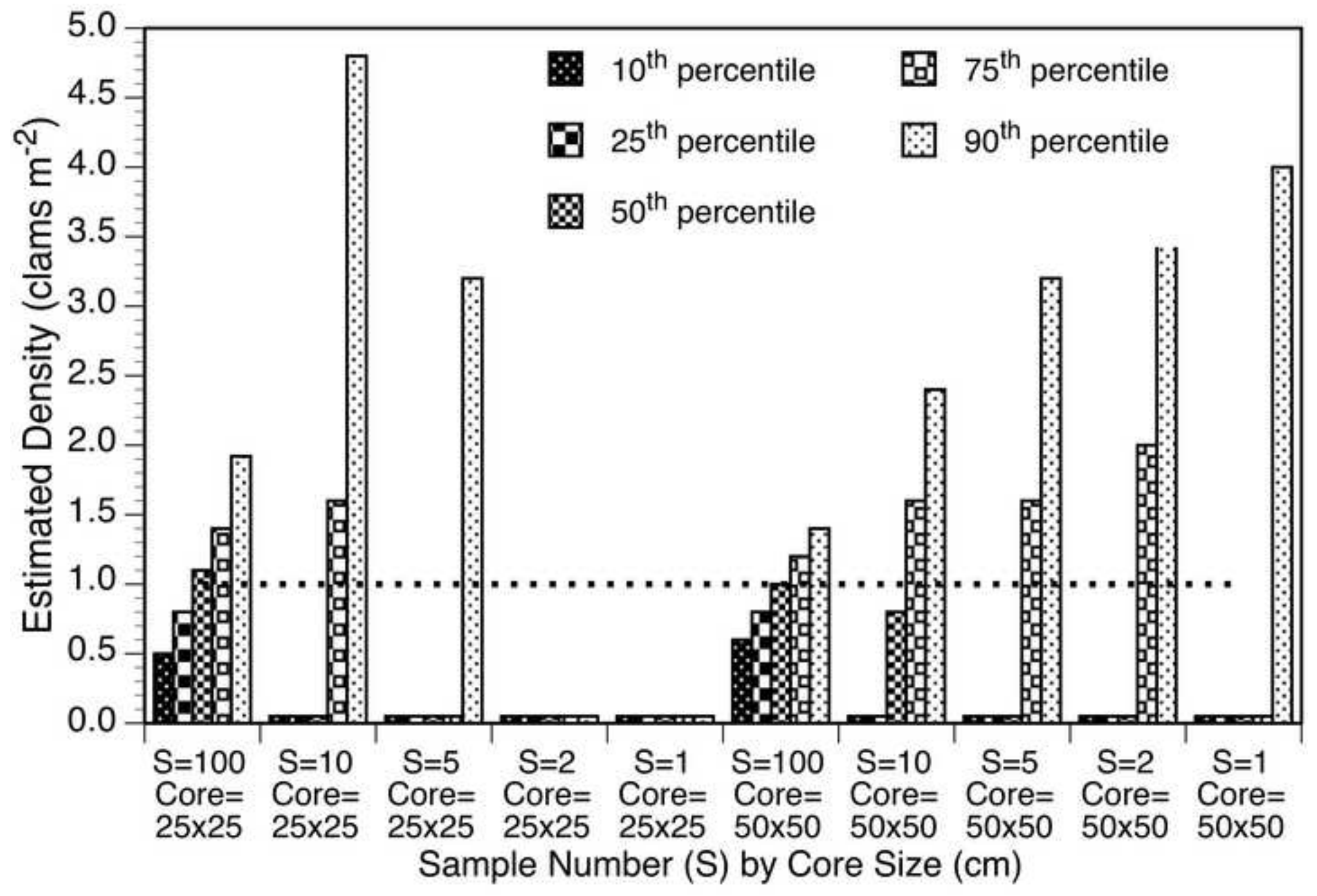




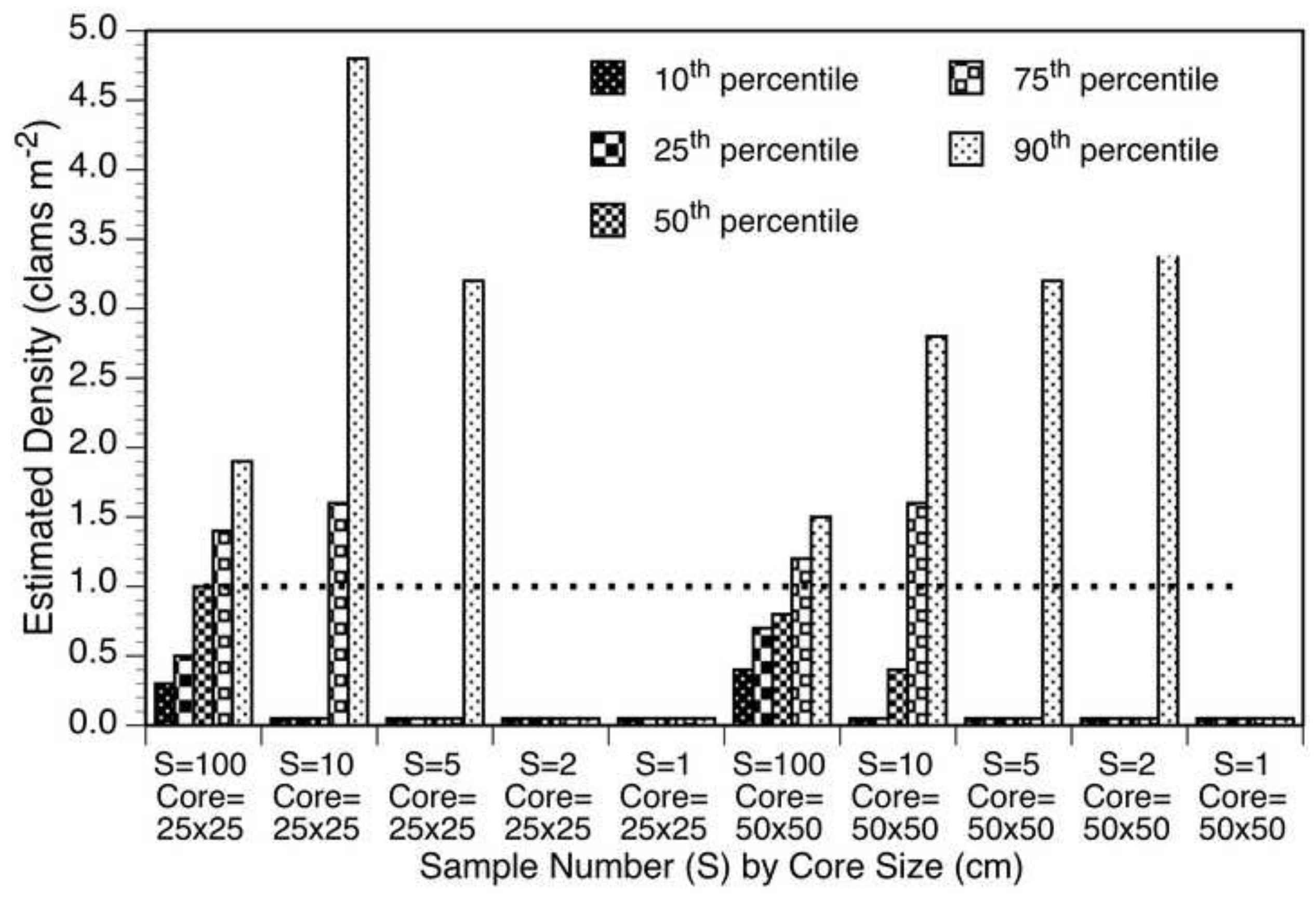




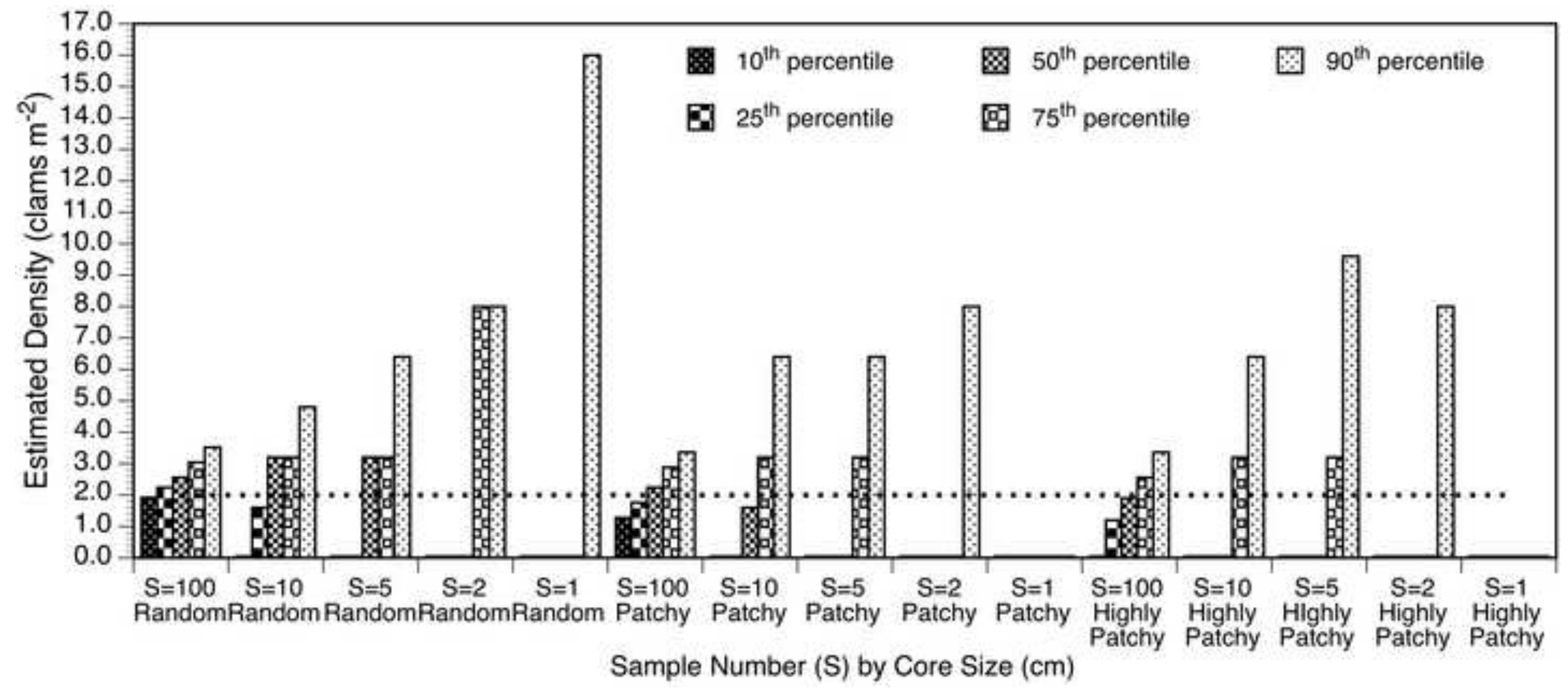




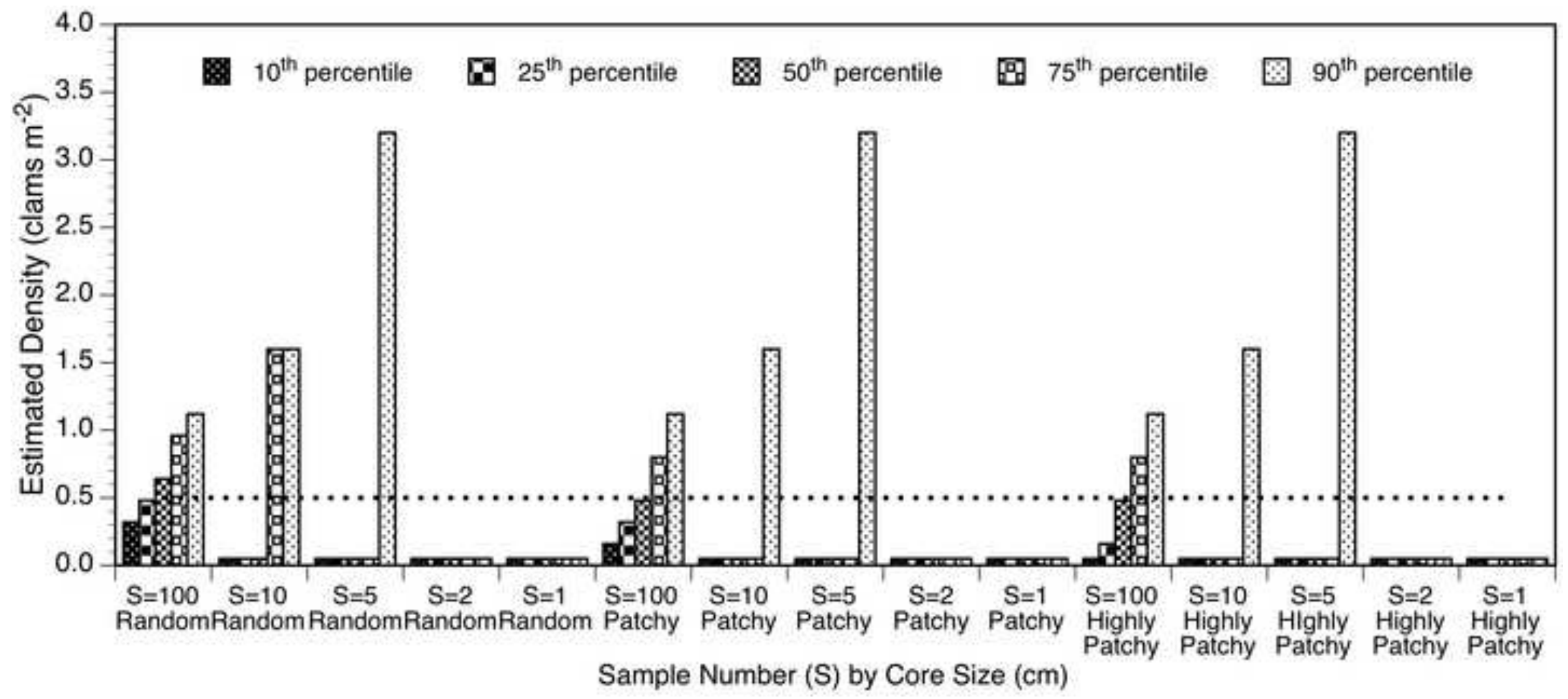

